spine become more acute, their first part from the head to the angle taking a course too directly backward; the body of the bone from the angle onward is directed too much forward, the whole rib being a segment of too small a curve. On the left (concave) side the first part is directed too little backward, the body ruas too little forward - in other words, takes too outward a course; the angle, therefore, is too obtuse, and the whole bone too straight, forming a segment of too large a curve. The changes, therefore, on each side, directly the reverse of one another, are in each instance the continuation further afield of the alterations which I described ${ }^{3}$ as taking place on the pedicles and transverse processes. But besides these alterations of form, besides the backward projection of the right and forward yielding of the left ribs other changes of position must be noted-viz., as lateral deviation of the vertebræ becomes marked, and, indeed, as a necessary sequela of that deviation, the thoracic rings become oblique in different directions. The condition may be illustrated thus: suppose seven vertebræ, from the third to the ninth dorsal, to be affected, the second arnd the tenth being on the median line and straight, the ninth, eighth, and seventh slope over to the right and stand oblique, the sixth, however, is perpendicular, while the fifth, fourth, and third slope back towards the middle line or towards the left, and stand in an obliquity of contrary direction to that of the three lower of our series. Hence, in the left (concave) side the ribs are on the axillo-iliac line packed close together. The middle rib of the series may be taken as normal ; but above this they slope too much downward ; below it, too much upward. On the right (convex) side the contrary conditions obtain; the basket-work of the chest is too open; the ribs below the most deviated vertebra slope too much downward, those above it too much upward. Thus, to sum up, the ribs undergo three sets of changes(1) changes of form, (2) changes of position connected with rotation of vertebræ, (3) changes of position connected with obliquity of vertebræ. Naturally, the whole shape of the thorax and of the upper part of the abdomen alters, and many disturbances of function, great loss of health, invalidism, with persistent pain, are thus produced. For the heart is, though often not displaced, yet thrown out of position, the respiratory movements are greatly restricted, the stomach and liver are pressed upon and disturbed. Moreover, the figure becomes considerably, in the worst cases hideously, distorted. I have seen instances in which the ninth and tenth ribs lay within the venter of the ilium well below the crest, and it is not at all unusual to find the angles of the ribs, altered as above described, forming a conspicuous prominence, often taken, previous to closer examination, for the usual "humpback" of angular curvature. These conditions came on slowly in an uncared-for or mistreated case. Thus advanced they are incurable, though relief and alleviation can be afforded; but the very slowness of their advent gives great opportunities for, and shows the high importance of, early and rational treatment, such as I shall describe in my next paper.

\section{ON TWO CASES OF}

VAGINAL EXTIRPATION OF THE UTERUS FOR CANCER;

WITH REMARKS ON THE OPERATION.

BY JAMES BRAITHWAITE, M.D. LOND,

OBSTETRIC PHYSICIAN TO THE LREDS GENERAL INFIRMARX, AND IJECTURER ON DISEASES OF WOMEN AND CHILDREN AT THE LEEDS SCHOOL OF MEDICINE.

Ir is now generally admitted that it is unnecessary, and indeed in most cases a mistake, to remove the uterus for cancer of the cervix alone. The tendency of cancer of the cervix is not to spread upwards towards the body of the uterus, but outwards through the thickness of the neck, so as to involve the cellular tissue. It is only when the disease commences near the os internum that it is likely to spread upwards beyond the cervix. This is a pathological fact of the greatest practical importance. It is now, in this country at any rate, generally agreed that it is only in cancer of the body of the organ, or in some cases commencing close to the os internum, that removal of the whole uterus is called for, or even justifiable. In cancer of the cervix not too far advanced for operation it is only necessary to divide the vagina from the cervix all round, and remove as much of the lower portion of the uterus as may be required to cut well beyond the disease. Almost any portion of the uterus short of the whole may be thus removed without opening the peritoneum. At the Leeds Infirmary we have for some timesupplemented this operation by removing a further portion of uterine tissue by the use of chloride of zinc. This is followed by great contraction of the cicatrix. This "supravaginal amputation of the cervix" might with some justice be called "Baker's operation," as it was first described by Dr. W. H. Baker, of Harvard University, in the American Journal of Obstetrics of April, 188\%. The mortality from this operation is very low ( 7.8 per cent.), and it gives equally good results as to freedom from recurrence in cases of cancer of the cervix, and when, or if, recurrence does take place is is very rarely in the stump of the uterus, but in the surrounding cellular tissue. In this paper I shall not again allude to this operation, as it concerns only cases for which it is not sufficiently radical. It is, of course, only possible to treat cancer of the body of the uterus by the removal of the whole organ, and it is now well established that this should be done by the vagin 11 method (kolpo-hysterectomy) whenever possible, and that what is known as Freund's operation, or removal of the uterus by abdominal section, with its mortality of 72 per cent., should be employed only in exceptional cases.

The two cases which form the subject of this paper were both primary cancer of the body of the uterus. I propose to relate them somewhat briefly, and subsequently to give more fully some details of the operation.

CAsE 1.-This patient was thirty-eight years of age. She had had several children, the last being twins, three years before her admission to the infirmary in October, 1885. She was in bad health from loss of blood, which had been going on for a year and a half, in spite of the removal of a polypus in July, 1884. The uterus now again contained a polypus, which, although it had a comparatively narrow neck, grew from a widely extended base on nearly the whole of the anterior wall and fundus. The microscope showed this to be a round-cell sarcoma. The uterus was freely movable, and the disease had probably not extended beyond it

On Nov. 14th, 1885, with the able assistance of Mr. Mayo, who was then resident surgical officer, and of $\mathrm{Mr}$. Croft, our present resident obstetric officer, I removed the uterus entire per vaginam. Having separated it from its vaginal attachments all round and from the bladder anteriorly, and the peritoneal cavity being opened before and behind, the fundus was retroverted through the posterior wound. I had intended at the same time to push the cervix up through the anterior wound, but found it easier to bring the whole organ out at the vulva, when it lay fully exposed to view the fundus pointing downwards and the cervix upwards as the patient lay in the lithotomy position. The only attachments were the broad ligaments, the vaginal bases of which had been divided, and these being healthy and elastic there was no difficulty in doing this. Had it not been for an unfortunate accident which now occurred, the operation would have been quickly concluded; but finding that I had not separated the uterus from the bladder sufficiently at the sides of the anterior wound, I widened it by tearing through the cellular tissue a little at each side with the finger. This must have thrown too much strain upon the coats of the bladder, weakened by its separation from the uterus, and a small laceration took place, of which I was not aware until later in the operation. The broad ligaments were now tied in two parts, including, of course, the Fallopian tubes and round ligaments, and the uterus was cut away. It was necessary to tie two vessels in the stumps of the broad ligaments. I now found out the laceration of the bladder, which was about three-quarters of an inch in length and transverse. This was closed by sewing the peritoneum over it to the anterior vaginal wall by a continuous suture, and as it was near the edge of the vaginal wound, it was also included with the peritoneum covering it in the catgut sutures by which the anterior and posterior vaginal walls were alternately brought together. The patient was in such a condition that her death before the conclusion of the operation was possible, and no time was lost which could be avoided, the whole being concluded in one hour and ten minutes. A slow but complete recovery ensued without the occurrence of any unfavourable symptoms. I thought $I$ had made the wound in the bledder quite safe, but a fistula nevertheless resulted. In the following Iune 
the patient was readmitted and the fistula closed. It was Tery ineccessible, as it could not be pulled down into view like an ordinary fistula, and it was not an aperture, but a small funnel-shaped canal at right angles to, and at the summit of, the vagina.

The patient was heard from thirteen months after the operation. There was no return of the disease, she could retain her urine, and was in fair health.

CASE 2.-Mrs. L- widow, aged fifty, recently a cook in domestic service; never pregnant. She had suffered from excessive menstruation for four years; no pain until recently. On examination of the abdomen a rounded and somewhat nodulated tumour was felt nearly central, and ateaching four inches above the pubes. This was found to be the uterus, the mouth of which was closed. The cervix having been dilated, it was ascertained by the aid of the finger that the growth had the clinical characters of cancer of the interior of the body, extending downwards into the cervix, but not actually implicating the lips of the uterus. This was confirmed by microscopic examination. The organ was fairly movable, but not as freely as in the preceding case. No extension of the disease to the surrounding cellular tissue could be made out.

On March 19th last, assisted by Mr. Harry Littlewood, the resident surgical officer, and Mr. Croft, the resident obstetric officer, I removed the uterus entire per vaginam. After separating the vaginal attachment all round, and separating the uterus from the bladder, and opening the peritoneum before and behind, it was found impossible to retrovert the uterus through the posterior wound owing to its size, and therefore impossible, of course, to bring it down into riew as in the first case. It was removed without any particular difficulty in the following manner: Being well pulled down, the broad ligaments were ligated and divided in segments first on one side and then on the other. A Spencer Wells' long-handled needle was used. Each portion of broad ligament divided allowed the uterus to be brought a little lower, in a zigzag fashion. No hæmorrhage occurred from the cut surfaces on the uterine side, although not protected by any ligature. The fundus was then brought down into view, one cornu first, and the Fallopian tubes and round ligaments ligated and divided, and the uterus completely separated and removed. It was now ascertained that the disease had spread up the right tube, and a coil of intestine, which was visible, was seen and felt to be studded with small cancerous nodules. Had it not been for the state of the bowel I should have at once opened the abdomen and removed the tube. The vaginal wound was brought together precisely as in the first case, the peritoneum being in both cases included in the sutures. The only difference was that at each side of the drainage tube were four smaller stumps instead of two larger ones. Each suture fastened in the wound two stumps. The silk-constricting sutures on the stumps were left about two inches long.

The patient recovered without a bad symptom of any kind. The temperature, which had been $102^{\circ}$ and over before the operation, fell to $101^{\circ}$ and $100^{\circ}$ on the two succeeding days. The drainage tube was removed on the fifth day, and all the silk ligatures on the pedicles or stumps eame away on the thirteenth and fourteenth days. Of course, the recovery of this patient is only temporary, but her death will be less painful than it probably would have been from cancer of the uterus itself ; and meanwhile she has a short reprieve, for she was up and walking about in three weeks and a half, and is now at a convalescent hospital, feeling and looking fairly well. Probably the implication of the tube and bowel was recent, and if the case had been seen earlier, the ultimate result, which is unfortunately too certain, would have been different.

This operation has now, I believe, been performed over 400 times, and the records of a large proportion of these cases are accessible. Almost every conceivable variation in the details of the operation has been made. I propose, whilst giving more in detail the plan of operation followed in the two cases related, to allude to some of these variations, especially as the plan of operation recommended is not that of any one operator, but consists of what appear tn me to be the best parts of all, combined so as to form a practical whole, with the addition of some points which, so far as I can ascertain, are new, but seem to me of practical importance and likely to conduce to success. The simpler the operation can be made, consistent with safety from hæmorrhage, the greater will be the success, because these patients are generally in bad health from hæmorrhage, and the duration of the operation is a very important factor.
Next to the duration of the operation the most important or equally important, object $w \theta$ should have in view is to keep the poritoneum free from contamination with septic and cancerous matter from the uterus.

I notice that the leading idea of most operators has been to avoid hæmorrhage. This I take to be a mistake, for the application of temporary ligatures and clamps, or pressure forceps, takes up time and is generally unnecessary. Forcible dragging of the uterus downwards arrests the circulation, as proved by the absence of hæmorrhage from the uterine side of the divided broad ligaments. It is advisable to prepare the parts by removing with a curette any loose cancerous masses in the neck a few days before the operntion and by the use of cleansing antiseptic injections. The patient being in the lithotomy position, and the vagina washed out with rather hot water, for the purpose of preventing hremorrhage as well as for the sake of cleanliness, in both cases I scratched with a suitable instrument the exact line of the anterior and posterior vaginal fornices. This gives the situation of the incisions, of which the anterior is important. The uterus being now pulled down into view by vulsellum forceps, the posterior incision should be made first. After an aperture is made through the vaginal wall the left index finger is to be passed through to serve as a guide to the scissors with lateral angle, with which the division is completed on each side quite up to the bases of the broad ligaments. Whilst the scissors are used the traction by the vulsellum should be relaxed. Now let traction be again made, and with a scalpel divide the anterior vaginal wall by a semicircular incision in the line of the anterior fornix just to reach the cellular tissue, so abundant here in front of the cervix. Let this incision be prolonged laterally to join the posterior incision at each side, but here the depth of the incision must not be more than one-sixth of an inch, and exactly five-sixteenths of an inch from the cervix.

The next step is to separate the bladder from the uterus, and, being warned by the experience of the first case, in the second I did not use the finger for the purpose of tearing through the cellular tissue. The finger, although sensitive, does not give the nicety required. There can be no better instrument for the purpose than an ordinary uterine scarifier a little bluntened. The small flat blade of this partly cuts and partly tears through the cellular tissue without throwing any strain on the bladder, the walls of which are very tender, being weakened by their separation from the uterus. When the finger is in the anterior wound and a catheter is introduced into the bladder, it will be felt how very thin the bladder wall is. When the peritoneum is reached, it is at once opened by the scarifier, or scratched through by the finger-nail, and the wound is then to be widened with the scarifier from side to side, until a finger in the anterior wound will meet a finger in the posterior wound at each side of the uterus, the broad ligaments only intervening. This is important on account of afterwards ligating the broad ligaments, and it cannot be done unless the posterior wound is made first.

When the anterior wound was made the peritoneum was opened, but when the posterior wound was made in both cases it was left intact, thereby preventing access of blood, cancerous or septic matters. This is a point of the greatest consequence. Before it is opened (which must now be done), the parts must be washed clear of everything. It may be inferred from most accounts of operations that this has not been thought of, but some operators have with the same object made the posterior wound last. The plan I have indicated, however, answers the end required better, for in making the anterior wound, which is a matter of delicacy, it is an advantage to be able to insert a finger into the posterior wound, especially in order to gauge the proper width of the anterior wound, and to steady the parts whilst it is made. The peritoneum is quite loose over the roof of the vagina posteriorly, so that it is actually difficult to open it as it yields before the finger.

Nearly all operators now either bring down the fundus through the posterior wound or through the anterior one. The former plan is obviously the best, because there is more room posteriorly; but I believe both plans are bad, because the cervix is pushed up as the fundus comes down, and by this somersault the cervix with its hurtful discharges has the chance of infecting the peritoneum. To avoid this Mr. Greig Smith of Bristol, who reports a case in THe LA NCET of Jan. Ist of this year, even passed a sponge into the peritoneal cavity. The plan of removing the uterus cervix first avoids all risk to the peritoneum. It is the plan followed by Billroth and Martin, but the former ligates the ligaments by 
mass ligatures-a more difficult and tedious and less secure way than that of ligating them in segments. The plan of bringing the uterus entirely outside adopted in my first case has the advantage of exposing everything fully to view, whilst equally with the plan of removing the uterus cervix first, directly downwards, it avoids the risk of septic infection of the peritoneum. It can only be done when the broad ligaments are elastic and free from any trace of past cellulitis, and when the uterus is not much enlarged. It is not mentioned by any writer on this subject as possible, nor in any account of operations which I have seen is it mentioned, except that Staude has published some cases in which, without the anterior wound being made at all, the fundus was retroverted through the posterior one, the cervix being thus not anteverted, as usual, and then, lastly, the anterior wound was made.

In order to avoid injury to the ureters, their exact distance from the cervix must be borne in mind. This is the merest fraction under half an inch. They are nearest the cervix, quite at the lowest part of the broad ligaments, and higher up three-quarters of an inch from the side of the uterus. This space is very small. It can be made a trifle larger by firmly grasping the broad ligament between the finger and thumb, when the ureter being of firmer structure than the surrounding parts escapes or is squeezed outwards a little. But we have to cut our coat according to the cloth, and it is absolutely necessary for the lowest ligature to be not further from the cervix than five-sixteenths of an inch. The uterus being now removed, we must sponge out the vagina and get an idea of the position and appearance of the wound. The left index is to be passed in to pull down the peritoneum anteriorly and posteriorly. The anterior is most important. With an Emmet's long needle-holder, and one of his needles, which, however, should be made an inch and a quarter in length, and curved slightly (to be had of Mayer and Meltzer, Bond-street, Leeds), a strong catgut suture is to be passed through the edge of the vaginal wall on the extreme right of the wound then in order through the posterior flap of peritoneum, through two pieces of broad ligament stump (at opposite edges, so that they may not lie superimposed in the wound), through the anterior flap of peritoneum, and lastly through the anterior vaginal wall. These sutures should pass through the stumps at the further side of the constricting silk ligatures, so that when the wound is closed the latter are extraperitoneal. Two similar catgut sutures at each side of the supra-vaginal wound are sufficient to bring it together and to fasten the pedicles in the wound. A drainage tube should be placed centrally, and fixed to the posterior vaginal wall low down by a suture. It can easily be removed by cutting this suture, without any disturbance or exposure of the wound. The ends of the catgut sutures which bring together the supra-vaginal wound should be cut short, but those of the silk constricting ligatures on the stumps should be left an inch and $\mathrm{a}$ half long and lying loosely in the vagina. These will come away in ahout a fortnight. The vagina, and especially the wound, should now be dusted lightly with iodoform, and the vagina plugged loosely with iodoform gauze. The drainage tube should be cut off so that the end is well within the vagina, lest air should enter the peritoneum. The end of the tube is to be packed round with absorbent wool. One advantage of leaving the silk ligatures on the pedicles so long is that in the event of secondary hæmorrhage the end of each pedicle could be examined separately by sight and any bleeding vessel taken up.

Much attention has been given by writers on this operation to the two questions of whether the peritoneum should bo included in the sutures closing the vaginal wound, and whether a drainage tube should be used. A conclusion on these points can hardly be helped by elaborate statistics, for our knowledge of peritoneal wounds is quite sufficient from other sources to teach us that the peritoneum flaps should be brought down and included in the wound ; but the result of statistics proves this almost foregone conclusion. There are other ways of doing this, as by using a continuous suture, which is said to be more quickly done, but I think this would seal up the parts rather too firmly. A little capillary exudation should be allowed.

There have been many modifications of the operation which seem to me should be condemned. Such as removal of the cervix at the commencement of the operation, the use of mass ligatures either as temporary or permanent means of arresting hæmorrhage from the broad ligament, relying upon pressure forceps instead of ligatures for the same purpose, the use of elastic ligatures, putting ligatures on the broad ligaments with the uterus in situ, unnecessary igating the vaginal roof before incising it, and especially leaving the vaginal and peritoneal wounds unclosed. On the other hand, the plan of bisecting the uterus and removing one half first, which has been followed by Müller of Vienna, $Z$ weifel, and by Alexander Simpson of Edinburgh is a modification worth bearing in mind.

In conclusion, my object in this paper has been to try to work out the minute details of this operation, choosing from the various plans which have been previously followed those parts of each which seem most likely to conduce to success. It seems not improbable that the mortality may be considerably reduced. If it is properly done, there seems to me very little for the patient to die from, for the peritoneum can be guarded from sepsis by the methods I have indicated, and hæmorrhage can also be with great certainty prevented. Moreover, if the pedicles are treated extra-peritoneally and peritoneal surfaces everywhere lie together in the wound, it will be shut off almost at once from the general peritoneal cavity. By far the greatest number of these operations have been done on the Continent, and especially in Germany; but this arises from their being done unnecessarily, when supravaginal amputation would have given equal security with much less risk. For instance, out of nineteen cases of Fritsch's, sixteen were cancer of the cervix and only three of cancer of the cervix with enlargement of the body. The same proportion holds good with most German operators. In this country the operation has been performed comparatively seldom; but it has been generally confined to suitable cases-viz, cancer of the body or of the neck at its upper part. In Yorkshire it has, I believe, only been done four times, and the two cases related were the only successful ones; but I say this open to correction.

\section{COMPARATIVE EXPERIMENTS BETWEEN} THE ACTION OF PAPAIN (FINKLER) AND PEPSINE.

Br DR. D. FINKLER, PROFBSSOR AT THE UNIFERSITY OF BON

PaPAin (Finkler) is a ferment which is manufactured according to my specification from the plant called Carica papaya. It is an albuminous body, which under certain conditions can change albumen into peptone. The conditions which produce this change are very different from those under which pepsine and pancreatine produce the same effect. In order to demonstrate the effect of papain $\mathrm{I}$ shall indicate various experiments made by myself which will give an exact insight into the conditions of the effect and also a comparison of the effect of pepsine. For these comparative trials I used a pepsine of known best quality, most of the commercial pepsines being decidedly weaker than the one I used.

\section{Has Papain Reality a Digesting Property?}

Experment 1.-(a) Five grammes raw minced meat, 50 c.c. water, 5 c.c. of a 1 per cent. papain solution ( 1 gramme in 100 c.c. water). This mixture was put into the oven and kept for twenty-one hours at $38^{\circ}$ Centigrade; it was then filtered. The filtered portion contains the albuminous substance of the meat turned into peptone, which is not precipitated by nitric acid, nor by ferrocyankalium or acetic acid; it is precipitated by tannic acid. The xanthoprotein and biuret reactions are well shown. The non-peptonised residue of the meat weighs when dried $0 \cdot 1$ gramme; therefore 90 per cent. of the solid portion of the meat has been dissolved in water. Of the albuminous substances of the meat, 87 per cent. were peptonised-which shows a very energetic degree of digestion. (b) For comparison, 5 grammes raw minced meat, 55 c.c. hydrochloric acid $(0.2$ per cent.), and 5 c.c. of a 1 per cent. pepsine solution were treated as. above. After twenty-one hours, $70^{\circ} 6$ per cent. of the albuminous substance of the meat was peptonised.

Experiment 2.-(a) Five grammes meat, 50 c.c. water, 0.5 c.c. of a 1 per cent. papain solution. After forty hours the non-peptonised residue of the meat weighed 0.19 gramme; of the albumen of the meat $77 \cdot 7$ per cent. was peptonised. (b) Five grammes meat, 50 c.c. hydrochloric acid $(0.2$ per cent.), 0.5 c.c. of a 1 per cent. pepsine solution. After forty hours the non-peptonised residue weighed 0.19 gramme; of the albumen of the meat 77.7 per cent. was peptonised. 